\title{
Urgensi Metodologi dalam Sejarah Keilmuan: Sebuah Pengalaman Lampau Tradisi Ilmiah Islam
}

\author{
Anwar Nuris \\ Sejarah Kebudayaan Islam IAIN Syekh Nurjati Cirebon \\ Email: anwarnuris00 gmail.com
}

\begin{abstract}
Islam as a civilization has make a full picture about the methodological process of Islamic studies. That process have confirm how important a methodology in basic making of islamic civilization. The methodology can make a new perspective in theory formulization. This is very important, remembering the methodological tradition in classical islamic treasury has a long history and regarded as foundation in islamic basics intellectual. Of course, if not the formulation, the principle and spirit usually have the meaning in living today.
\end{abstract}

Keywords : Scientific, Islam, Tradition

\section{Pendahuluan.}

Sejarah, jika dipandang lebih sebagai khazanah daripada anekdot atau kronologi, dapat menghasilkan transformasi yang menentukan citra dalam sains yang merasuki kita sekarang. Citra itu telah dibuat sebelumnya, bahkan oleh para ilmuwan sendiri, terutama dari studi tentang pencapaian ilmiah yang tuntas seperti yang direkam dalam karya-karya klasik dan, yang lebih baru, dalam buku-buku teks yang dipelajari oleh setiap generasi ilmuwan yang baru untuk mempraktekkan kejuruannya. Buku-buku tersebut juga hampir selalu dibaca sebagai mengatakan bahwa metode-metode ilmiah itu semata-mata apa yang dilukiskan dengan tekhnik-tekhnik manipulatif yang digunakan dalam mengumpulkan data-data buku teks, bersama-sama dengan 
operasi-operasi logis yang digunakan ketika menghubungkan data-data tersebut dengan generalisasi-generalisasi teoritis dari buku teks itu. Hasilnya ialah sebuah konsep sains dengan implikasi yang sangat menonjol tentang sifat dan perkembangannya. ${ }^{1}$

Dalam Islam, Muslim telah mencari Tuhan didalam sejarah. Kitab suci mereka, Al-Qur'an, memberi mereka misi historis. Tugas utama mereka adalah membentuk komunitas yang seluruh anggotanya - walaupun yang paling lemah sekalipun - diperlakukan dengan rasa hormat. Pengalaman membentuk masyarakat seperti itu dan hidup didalamnya akan memberi mereka kedekatan dengan sifat ketuhanan, karena mereka akan hidup sesuai dengan kehendak Tuhan. Seorang Muslim harus menyelamatkan sejarah, dan itu berarti bahwa urusan-urusan negara tidak menghalangi kehidupan spiritualitas tetapi merupakan bagian dari agama itu sendiri. Pengetahuan politik bagi umat Islam merupakan sesuatu yang sangat penting. Seperti citacita agama lain, sulit sekali melaksanakannya dalam kondisi sejarah yang tragis dan penuh kekurangan, tetapi setelah mengalami kegagalan demi kegagalan, umat Islam harus bangkit dan memulai lagi. ${ }^{2}$ Semua usaha harus dilakukan untuk mengembalikan sejarah Islam pada jalurnya. Jika tidak, seluruh kerajaan agama akan runtuh, dan kehidupan akan menguap tanpa makna. Seorang Muslim akan menghubungakan peristiwa-peristiwa pada masanya dengan masa lalu sebagaimana orang Kristen merenung dibawah patung suci dan menggunakan imajinasi kreatif untuk menemukan inti sifatsifat ketuhanan yang tersembunyi. Jadi, nilai sejarah eksternal orang-orang Muslim bukan pusat perhatian kedua, karena salah satu karakteristik utama Islam adalah pensakralan sejarah. ${ }^{3}$

Kaledioskop peran dan fungsi sejarah dalam tradisi Islam merupakan salah satu wujud konkret responsibilitas Islam sebagai sebuah peradaban terhadap tantangan zaman. Jargon Al-Muhafadhotu 'ala al-Qadimi as-Shaleh wa al-akhdu bi al-Jadidi al-Ashlah mencoba memerikan sikap dan upaya bagi setiap Muslim untuk menghadapi era global. Jadi, menurut pesan tersirat

\footnotetext{
1 Thomas S. Kuhn., The Structure of Scientific Revolutions: Peran Paradigma dalam Revolusi Sains, (Bandung: PT.Remaja Rosda Karya, 2000) hal.1.

${ }^{2}$ Karen Amstrong, Islam: a Short History, (Surabaya: Ikon Teralitera, 2004) hal.vii.

${ }^{3}$ Karen Amstrong, ibid, hal. ix.
} 
dalam jargon tersebut, seorang Muslim cukup dengan melakukan upaya "rereading" terhadap sejarah yang pernah ditorehkan oleh Islam sebagai sebuah peradaban, terutama pada abad kedelapan hingga akhir abad kelima-belas dimana tidak sedikit sejarawan dunia menyepakati bahwa pada abad-abad inilah Islam mencapai puncak kejayaan dalam dunia keilmuan.

Belum lagi, implan fakta-fakta empirik yang begitu melekat dalam benak kita tentang penemuan-penemuan mutakhir dunia keilmuan belakangan ini yang juga memberikan penguatan terhadap kebenaran atas fakta-fakta yang telah termaktub dalam kitab suci Al-Qur'an. Kasus semacam penelitian terhadap karakteristik air oleh seorang peneliti Jepang dapat diajukan sebagai contohnya. Seberapa besarkah tingkat keakuratan dan relevansifitas zaman keemasan Islam sekitar 15 abad silam dalam konteks dunia maya abad 21 ini ketika dibingkai dalam frame reaktualisasi? Jawaban atas pertanyaan ini hanya akan terjawab dengan jitu dalam proses realisasi jargon islami diatas yang akan dilakukan oleh umat Islam, lebih-lebih oleh sarjana-sarjana Muslim sebagai salah satu tanggung-jawab kesarjanaannya.

\section{Tradisi Ilmiah Islam}

\section{a. Tradisi IImiah dalam Tradisi Islam.}

"Dari abad kedelapan hingga akhir abad keempat belas, ilmu pengetahuan Arab (Islam) barangkali adalah sains yang paling maju di dunia, yang jauh melampaui Barat dan Cina". ${ }^{4}$ Asumsi Toby E. Huff ini memberikan indikasi kuat bahwa peradaban Islam pernah tumbuh secara dominan dan berkembang dalam konstelasi peradaban umat manusia. Fakta dasar pendukung keabsahan asumsi ini adalah dominasi ilmuwan/filosuf muslim dalam praktek-praktek ilmiah yang telah dilakukannya.

Sejatinya, tradisi ilmiah dalam tradisi Islam telah dimulai sejak Nabi Muhammad saw menjalankan misi dakwah-nya terhadap masyarakat Arab pada abad ketujuh hijriyah. Hanya saja, proses pembentukan karakter ilmiah dalam Islam digagas pada saat pendirian institut penerjemahan Bayt al-

\footnotetext{
${ }^{4}$ Toby E. Huff., The Rise of Early Modern Science, Islam, China and the West, (New York:Cambridge University Press, 1995) hal.48.
} 
Hikmah oleh khalifah Abbasiyah Al-Ma'mun pada abad kedelapan. Pendirian Bayt al-Hikmah ini mendapat dukungan penuh dan dana yang tidak sedikit dari khalifah Al-Makmun untuk dijadikan sebagai pusat riset dan penerjemahan terbesar di Baghdad pada masanya. Dalam insitut penerjemahan Bayt al-Hikmah ini, J. Pederson menyinggung tiga tokoh yang menonjol yaitu Salim dan dua rekannya Sahl bin Harun dan Sa'id bin Harun. Selain mereka ada seorang berkebangsaan Persia yang menonjol, yaitu alKhawarizmi yang telah berhasil membuat sebuah karya dibidang astronomi berdasarkan tulisan-tulisan orang-orang India. ${ }^{5}$ Profesor A. I. Sabra dengan baik menggambarkan proses dan kegiatan penerjemahan dalam Bayt alHikmah ini serta sumbangan al-Makmun terhadap aktifitas ilmiah yang luar biasa ini sebagai berikut:

Menurut tradisi dikatakan bahwa al-Makmun, seperti juga alManshur (138-9/1754-5) dan al-Rasyid (170-94/786-809) sebelumnya, telah memperoleh buku-buku ilmiah dan filosofis dari Byzantium, untuk kemudian diterjemahkan. Koleksi yang lain dikatakan telah datang dari Syprus. Koleksi-koleksi ini sebenarnya telah dihimpun secara gradual sejak akhir masa pemerintahan Bani Umayyah. Penerjemahan di Bayt al-Hikmah pada masa al-Makmun, menjadi kegiatan yang sangat terorganisir dengan lingkup dan ketelitian yang tidak pernah terjadi sebelumnya. Al-Makmun benarbenar dapat dikatakan telah memberikan semangat besar terhadap gerakan (penerjemahan) tersebut, yang telah menyebabkan sejumlah besar karya-karya ilmiah dan filsafat Yunani dapat dengan segera diperoleh oleh sejumlah besar sarjana-sarjana yang berbahasa Arab. ${ }^{6}$

Peran besar al-Makmun terhadap proses penerjemahan besar-besaran di Bayt al-hikmah ini kemudian dipandang sebagai patron terbesar filsafat dan saints sepanjang sejarah Islam. ${ }^{7}$

\footnotetext{
${ }^{5}$ J. Pederson, Fajar Intelektualisme Islam: Buku dan Sejarah Penyebaran Informasi di Bani Arab, (Bandung: Mizan, 1984) hal.151.

${ }^{6}$ Al-Sabra, "The Scientific Enterprise," dalam Bernard Lewis, The World of Islam: Faith, People and Culture, (London: Thames and Hudson, 1980) hal.181

${ }^{7}$ Muhammad Iqbal, The Reconstruction of Religious Thought in Islam, (New Delhi: Kitab Bhavan, 1981) hal.56.
} 
Pada abad kedelapan juga, Ibn Muqaffa' yang mengabdi ke khalifah alManshur (754-775) telah menerjemahkan dengan baik karya-karya sastra maupun filosofis ke dalam bahasa Arab. Diantara karya tersebut adalah Kalilah wa Dimnah, yang ia terjemahkan dari bahasa Pahlevi dari fable bahasa India karangan pujangga India Bidpei. Selain itu ia juga menerjemahkan Khudai-Namah, atau Sejarah Raja-raja Persia, dan juga Ayin-namah, Kitab Mazda, Biografi Anushirwan, dan sejumlah karya-karya sastra dan etik yang asli lainnya. ${ }^{8}$ 'Abdullah ini juga dipandang sebagai penerjemah karya-karya filosofis seperti Kategori-Kategori, Hermeneutika, dan Analytica Posteriora karangan Aristoteles, dan juga Isagoge karangan Porphyry. Pada masa ini pula beberapa karya Aristoteles, Almagest Ptolemius dan Element karya Euclid telah diterjemahkan.

Pada awal abad kesembilan, khususnya pada masa Harun al-Rasyid (atau ada juga yang mengatakan selama masa al-Manshur), sebuah risalah India yang terkenal, Sidhanta (Sindhind) diterjemhkan ke dalam bahasa Arab oleh Muhammad bin Ibrahim al-Fazari (w.806), yang dilaporkan sebagai orang pertama kali membangun astrolobe dalam Islam, dan salah seorang dari dua astronom Muslim awal. Kitab Quadripartitus karya Ptolemius, yang diterjemahkan oleh al-Bithriq pada masa al-Manshur, pada masa Harun ini telah diberi komentar oleh 'Umar bin Farukhan. ${ }^{9}$

Tetapi, seperti telah disinggung diatas pada masa al-Makmunlah penerjemahan besar-besaran terhadap karya-karya filosofis dan ilmiah dilakukan. Misalnya, karya-karya filsafat Galen, seperti Risalah tentang Demonstrasi, Sillogisme Hipotetik, Etika, kemudian parafrasenya dari Sofis, Parmenides, Cryatylus, Euthydemus, Timaeus, Stateman, Republik dan Hukum karya Plato, telah diterjemahkan oleh Hunayn bin Ishaq dan juga muridnya 'Isa bin Yahya kedalam bahasa Arab untuk pelindungnya Muhammad Musa. Informasi lain mengatakan bahwa ia juga telah menerjemahkan Timaeus dan Laws karya Plato.

\footnotetext{
${ }^{8}$ Majid Fakhry, A History of Islamic Philosophy, second edition (New York \& London: Columbia University Press, 1983) hal.6

${ }^{9}$ Majid Fakhry, ibid, hal.8
} 
Hunayn juga telah menerjemahkan karya-karya Peripatetik Galen, seperti Risalahnya tentang Penggerak yang Tidak Bergerak ke dalam bahasa Arab dan Syria dan Pengantar Logika hanya kedalam bahasa Syria. Jumlahjumlah Silogisme (The Numbers of Syllogism) ia terjemahkan ke dalam bahasa Syria, tetapi anaknya 'Ishaq kemudian menerjemahkannya ke dalam bahasa Arab. Selanjutnya 'Ishaq putra Hunayn ini dikatakan telah menerjemahkan kedalam bahasa Arab karya-karya Aristoteles seperti Categories, Hermenutica, De Generatione et Corruptione, Fisika, Etika dalam komentar Porphyry, bagian-bagian Metafisika, kemudian karya Plato Sophist, bagian-bagian Timaeus dan akhirnya De Plantis. ${ }^{10}$ Abad ini dan berikutnya memang banyak menghasilkan penerjemah-penerjemah agung, seperti Ibn Na'imah al-Himsi (w.835), Abu Bisyr Matta (w.940), Yahya bin 'Aidi (w.974), Qustha' bin Luqa' (w.900), Abu Ustman al-Dimasyqi (w.900), Abu Ali bin Zur'a (w.1008), juga disebut Ibn al-Khammar (murid terbaiknya Yahya bin 'Adi) dan terakhir astrolog-filosuf Tsabit bin Qurra' dari Harran. Terjemahan filosofis utama Qustha antara lain empat buku pertama Physica Aristoteles, Tentang Kejadian dan Kehancuran (On Generation and Corruption) (Buku I), dan karya Pseudo Plutarch Opinion of The Physicist atau Placita Philosopharum. ${ }^{11}$

Selain proses penerjemahan besar-besaran, aktifitas kajian-kajian ilmiah juga intens dilakukan oleh para ilmuwan/filosuf Muslim pada masa itu. Aktifitas kajian-kajian ilmiah ini dapat dilihat pada saat Ibn Sina berdebat dengan gurunya al-Natili,

Pada waktu itu Abu 'Abdullah al-Natili, yang mengklaim telah mengetahui filsafat, tiba di Bukhara, maka ayahku memintanya untuk tinggal di rumah kami dan mengabdikan dirinya untuk mendidikku. Sebelum ia datang, aku telah mengenal metode prosekusi dan perbantahan (rebuttal) sebagaimana yang dipraktekkan oleh ahli-ahli fiqih. Kemudian aku mulai membaca Isogage (Karangan Porphyry) dibawah bimbingan al-Natili. Dan ketika ia menyinggung definisi dari tentang genus, aku

\footnotetext{
${ }^{10}$ Majid Fakhry, ibid, hal.14

${ }^{11}$ Mulyadhi Kartanegara, Reaktualisasi Tradisi Ilmiah Islam, (Jakarta: Baitul Ihsan, 2006) hal.82
} 
mendatangkan pujian darinya karena telah memverifikasi definisi ini dengan cara yang belum pernah ia mendengarnya. Ia sangat takjub kepadaku, apapun problem yang ia kemukakan aku mengkonsepsikannya lebih baik darinya, sehingga ia menasehati ayahku agar aku tidak menyibukkan diri pada apapun kecuali belajar. Aku terus belajar sampai aku membaca bagian-bagian yang sederhana dari logika dibawah bimbingannya. Tapi untuk hal-hal yang lebih rumit ia tidak punya pengetahuan apapun tentang mereka. Akhirnya aku mulai membaca sendiri naskah-naskah dan mempelajari komentar-komentarnya sampai aku menguasai logika. Adapun kitab Elements karangan Euclid, aku membaca figur-figur lima atau enam pertama dibawah bimbingannya; kemudian aku berusaha menemukan solusi bagi bagian lainnya dari buku tersebut yang belum dibaca dengan usaha sendiri. ${ }^{12}$

Bentuk kajian ilmiah lain yang lebih formal adalah majelis falsafi Abu Sulayman al-Sijistani al-Manthiqi (w. 985) yang diselenggarakan di kediaman al-Sijistani sendiri. Di kediaman al-Sijistani inilah orang-orang terpelajar dari berbagai wilayah Dunia Islam berkumpul. Para anggota kajian al-Sijistani ini tidak hanya berasal dari kalangan Muslim itu sendiri, bahkan juga ada yang beragama Kristen, Yahudi dan Zoroaster. Dalam dokumentasinya tentang kelompok kajian al-Sijistani ini, Abu Hayyan alTawhidi ${ }^{13}$ menyebutkan bahwa De Anima karangan Aristoteles merupakan salah satu pelajaran formal yang disampaikan oleh al-Sijistani dalam majelisnya. Demikian juga al-Sijistani mendiskusikan topik-topik yang diambil dari Physica Aristoteles. Al-Tawhidi juga menambahkan bahwa majelis-majelis para sarjana ini selalu disertai dengan penyampaian kata-kata bertuah (al-Fawa'id) atau kata-kata hikmah yang sering diberi komentar dan

\footnotetext{
${ }^{12}$ William E. Gohlman (ed.), The Life of Ibn Sina (Sirah al-Syaikh al-Ra'is), (Albany: State of University of New York, 1976) hal. 21-25

13 Abu Hayyan al-Tawhidi adalah sastrawan besar abad X sekaligus murid setia Abu Sulayman al-Sijistani yang telah mendokumentasikan aktifitas kajian ilmiah majelis falsafi al-Sijistani kedalam ke dalam sebuah kitab yang berjudul Kitab al-Imta' wa al-Mu'anasah yang teridiri dari 3 jilid dengan 4o topik kajian yang berbeda-beda. Lebih lengkapnya lihat Joel L. Kraemer, Humanism in the Renaisance of Islam, (Leiden: E.J. Brill, 1992) hal. 191.
} 
penjelasan tentang makna yang tersembunyi didalam ucapan-ucapan tersebut. $^{14}$

Aktifitas ilmiah lain yang telah memberikan kontribusi besar terhadap perkembangan pemikiran di dunia Islam adalah penelitian-penelitian ilmiah yang telah dilakukan oleh para ilmuwan Muslim. Demi kemudahan, hasil karya penelitian yang telah dilakukan oleh para ilmuwan Muslim akan dikelompokkan sesuai dengan klasifikasi ilmu Ibn Khaldun (w.1406) dalam Muqaddimah-nya yang terkenal (yang juga merupakan pengantar komprehensif buku sejarahnya Kitab al-'Ibar) yang membagi ilmu pengetahuan kedalam al-'Ulum al-Naqliyah (Ilmu-ilmu agama) dan al-'Ulum al-'Aqliyah (ilmu-ilmu Rasional). Penjelasan singkat diatas telah mendeskripsikan bahwa umat Muslim pada abad kedelapan dan kesembilan cukup intens dengan dunia keilmuan. Banyaknya karya-karya tulis dan aktifitas ilmiah lain telah menjadi modal dasar bagi kebangkitan peradaban Islam pada saat itu.

\section{b. Basis Metodologis tradisi ilmiah Islam.}

Kebangkitan peradaban Islam sejak abad kedelapan ini lewat dunia keilmuan telah menjadi bukti bahwa Islam berikut ajaran-ajarannya senantiasa berbanding lurus dengan kemajuan. Menurut Prof. Dr. Mulyadhi Kartanegara ${ }^{15}$ zaman keemasan Islam ini diperoleh melalui siklus-siklus ilmiah sebagai berikut:

\section{Memburu Manuskrip}

Perburuan manuskrip-manuskrip karya ilmiah filosofis kuno, terutama Yunani merupakan salah satu faktor fundamental yang mendorong kemajuan ilmiah dalam dunia Islam. Perburuan manuskripmanuskrip ini mencerminkan kehausan para ilmuwan Muslim klasik akan pengetahuan. Upaya gigih yang pernah dilakukan oleh Hunayn dalam memburu karya-karya Galen di Aleppo hingga ke Irak, Syria, Palestina, dan Mesir merupakan bukti nyata akan semangat mencari pengetahuan

\footnotetext{
${ }^{14}$ Lihat al-Jahizh, Kitab al-Bukhala', (Jeddah: Dar al-Mathbu'at al-Haditsah, 1989)

${ }^{15}$ Mulyadhi Kartanegara, ibid, hal.76-115
} 
yang besar. Begitu juga dengan al-Biruni yang dikatakan telah mencari karya Mani Sifr al-asrar selama 4o tahun. ${ }^{16}$

2. Menerjemah

Kendatipun sering dianggap sebagai sesuatu yang sepele, kegiatan penerjemahan sesungguhnya telah memainkan peranan yang cukup penting dalam perkembangan dunia ilmu pengetahuan. Dua era renaisans dunia, yaitu renaisans Islam (abad ke X) dan renaisans Eropa (abad ke XIV - XV) muncul karena proses penerjemahan yang telah dilakukan pada abad-abad sebelumnya. Bisa saja kita beranggapan bahwa tanpa proses penerjemahan yang dilakukan pada abad kedelapan dan kesembilan masehi terhadap karya-karya asing, khususnya Yunani dan India ke dalam bahasa Arab, renaisans Arab sulit kita bayangkan. Demikian juga tanpa kegiatan penerjemahan karya-karya Arab ke dalam bahasa Latin dan Ibrani, renaisans Eropa (Italia) tidak bisa kita bayangkan terjadi. ${ }^{17}$

3. Menulis Komentar/Ringkasan

Fungsi utama dalam penulisan komentar atau ringkasan terhadap karya-karya Ilmiah adalah untuk membantu pembaca dalam memahami maksud penulis aslinya dalam tulisannya. Fungsi ini telah dirasakan oleh Ibn Sina ketika mencoba memahami Metafisika Aristoteles. Ia mengalami kesulitan untuk memahami karya Aristoteles ini sekalipun ia membacanya sebanyak 40 kali. Kesulitan Ibn Sina ini teratasi ketika ia memperoleh dan membaca komentar al-Farabi yang berjudul Maqashid $f i$ ma Ba'd al-Thaabi'ah (Maksud-maksud Metafisika), yang menjelaskan tentang maksud metafisika karya Aristoteles ini. ${ }^{18}$ Selain itu, Al-Farabi juga menulis komentar atas Analytica Posteriora, atas Analytica Priora,

16 Franz Rosenthal, Etika Kesarjanaan Muslim dari al-Farabi hingga Ibn Khaldun, (Bandung: Mizan, 1996) hal. 51

${ }^{17}$ Joel L. Kraemer, The Philosophy in the Renaissans of Islam Abu Sulayman al-Sijistani and His Circle, (Leiden: E. J. Brill, 1986) hal. 25

${ }^{18}$ William E. Gohlman, The Life of Ibn Sina, (Albany: State University of New York Press, 1974) hal.35 
komentar atas Isagoge, atas Topica (Buku II dan VIII), komentar atas Sophistica, De Interpretatione, dan De Categoriae. ${ }^{19}$

4. Menulis Karya Orisinil

Selain aktifitas membaca, tidak sedikit ilmuwan Muslim yang menulis karya-karya ilmiah asli. Menurut laporan, Al-Thabari "telah menulis empat puluh halaman setiap hari selama empat puluh tahun". Sedangkan Ibn Sina telah menulis Kitab al-Inshaf selama 6 bulan, yang memuat solusi terhadap 28.000 masalah filsafat. ${ }^{20} \mathrm{Al}-\mathrm{Kindi}$, sebagaimana yang telah dilaporkan oleh George Atiyeh, telah memiliki daftar karya sebanyak 46 halaman dengan jumlah judul sebanyak 270 buah yang terdiri dari 33 karya filsafat, 8 karya logika, 11 karya aritmatika, 8 karya sferika (geometri), 9 karya dibidang musik, 24 karya geometri, 19 dibidang sferika langit, 29 dibidang pengobatan (kedokteran), 10 dibidang astrologi, 16 dibidang polemik, 7 dibidang psikologi, 12 dibidang politik, 11 tentang meteorology, 9 karya dibidang magnitud, 4 karya ramalan, dan 34 karya campuran. ${ }^{21}$ Dan masih banyak lagi karyakarya orisinil para ilmuwan Muslim yang tidak memungkinkan untuk dibahas secara lengkap dalam tulisan ini.

5. Menyalin dan Destribusi Buku

Fungsi utama dari proses penyalinan, kalau saat ini, mirip dengan fungsi percetakan. Hanya saja, pada masa dulu proses penyalinan ini seringkali dilakukan secara langsung dari seorang ahli kepada para muridnya. Dikatakan bahwa ahli filologi, al-Bawardi (w.957) telah mendiktekan langsung dari ingatannya masalah linguistik sebanyak 30.000 halaman. Demikian juga dengan Abu Bakr al-Anbari (w.935) yang konon telah mendiktekan 45.000 halaman hadits Rasulullah dan telah mampu, menurut pengakuannya sendiri, menghafal 30 buku. $^{22}$ Disamping itu, proses pendestribusian buku-buku juga memegang peranan penting dalam pembentukan tradisi ilmiah Islam. Kios-kios dan

19 F.W. Zimmermann, Al-Farabi's Commentary and Short Treatise on Aristotle's De Interpretatione, (Oxford: Oxford University Press, 1987) hal.17

${ }^{20}$ L.E. Goadman, Avicenna, (London \& New York: Routledge, 1992) hal. 38-39.

${ }^{21}$ George Atiyeh, Al-Kindi: Tokoh Filosofi Muslim, (Bandung: Pustaka, 1983) hal.140-185

22 J. Pederson, ibid, hal.43. 
toko-toko buku sering juga dijadikan sebagai tempat membaca-tulis dan berdiskusi atau berdebat. Dikisahkan bahwa 'Umar Khayyam remaja sering menghabiskan waktunya untuk membaca karya-karya astronomi di toko buku milik kekasih ayahnya. Toko buku ini juga merupakan tempat yang sering digunakan untuk berdiskusi bahkan debat antara tokoh-tokoh besar pada zamannya. ${ }^{23}$

6. Rihlat dan Khalwat

Kegiatan ilmiah lain yang telah banyak menyumbang kemajuan ilmu pengetahuan di dunia Islam adalah Rihlah "wisata intelektual" dan Khalwat atau bertirah untuk sebuah perenungan yang mendalam di tempat-tempat terpencil (retreat).

Dalam sejarah intelektual Islam, semangat mencari ilmu telah mendorong banyak ilmuwan Muslim untuk melakukan perjalanan jauh, baik dalam rangka mencari seorang guru, atau sejumlah manuskrip, perluasan wawasan dan pengalaman. Tetapi dari sekian banyak ilmuwan yang melakukan perjalanan intelektual (intellectuall trip), tidak ada seorangpun yang dapat menandingi Ibn Battutah (w.1377) yang telah mengunjungi hampir seluruh dunia dan mencatatkannya dalam sebuah karya berjudul al-Rihlah. ${ }^{24}$

7. Diskusi Ilmiah \& Seminar

Sudah dapat diyakini bahwa aktifitas diskusi ilmiah dan seminar merupakan aktifitas yang memiliki peran penting terhadap perkembangan dunia keilmuwan dalam tradisi Islam. Pada zaman keemasan Islam, ada beberapa bentuk kegiatan diskusi ilmiah yang dilakukan. Seperti halnya diskusi-diskusi ilmiah yang diselenggarakan di majelis-majelis kajian di lingkungan istana al-Ma'mun yang biasanya dihadiri oleh para sarjana ternama pada saat itu. Ada juga majelis ilmiah yang sering diadakan oleh raja Ja'far al-Sijistani dengan para sarjana dan filosuf yang menjadi anggotanya.

\footnotetext{
${ }^{23}$ William E. Gohlman, ibid, hal.35

${ }^{24}$ Mehdi Nakosteen, Kontribusi Islam atas Dunia Intelektual Barat: Deskripsi Analisis Abad Keemasan Islam, (Surabaya: Risalah Gusti, 1996) hal. 69
} 
8. Tradisi Kritik

Salah satu kunci sukses keilmuan Islam adalah adanya semangat dan tradisi mengkritik yang luar biasa dikalangan ilmuwan Muslim. Sebuah contoh kritik yang dapat diajukan disini adalah kritik al-Biruni kepada Ibn Sina dan Aristoteles.

Polimath Abu Rayhan al-Biruni (w.1041) mempertanyakan teoriteori fisika Ibn Sina, yang dia tidak setujui. Kritik itu ia sampaikan dengan mengirimkan risalah, yang dikirimkan melalui seorang utusan, langsung kepada Ibn Sina, dan yang kemudian dibalas secara langsung oleh Ibn Sina. Dan ketika masih penasaran al-Biruni menulis kembali balasannya atas balasan Ibn sina. Dan dikatakan ketika Ibn Sina telah meninggal, korespondensi diteruskan oleh murid kepercayaan Ibn Sina. Selain terhadap teori fisika Ibn Sina, al-Biruni, dengan semangat kritiknya, juga mengkritik teori Aristoteles berkenaan dengan gravitasi. Ketika Aristoteles mengatakan bahwa sumber gravitasi itu dua: langit dan bumi, maka al-Biruni membantahnya dengan mengatakan bahwa sumber gravitasi itu satu saja, baik untuk air, api, udara maupun tanah. Apa yang menyebabkan satu benda mengapung diatas yang lain tidak karena sumber gravitasi yang berbeda, tetapi karena gravitasi spesifik substansi itu berbeda satu sama lain. Kritiknya inilah yang telah mendorong beberapa ahli untuk menyebut al-Biruni sebagai penemu awal teori gravitasi, yang kemudian dikembangkan oleh Isaac Newton. ${ }^{25}$

9. Eksperimen

Sebagai efek-logis dari sikap kritis yang dimilikinya, para ilmuwan Muslim tidak serta-merta menerima sebuah teori yang belum teruji. Pengujian terhadap sebuah teori banyak dilakukan oleh para ilmuwan Muslim dengan melakukan eksperimen-eksperimen ilmiah. Menurut Dr. Koslah, "Orang-orang Islamlah, dan orang Islam sendiri yang menciptakan metode ilmiah (metode eksperimen), menyempurnakan dan memperkenalkannya ke dunia Barat." ${ }^{26}$ Lebih lanjut ia menjelaskan

\footnotetext{
${ }^{25}$ Mulyadhi Kartanegara, ibid, hal.109.

${ }^{26}$ A. Koslah, The Miracle of Islamic Sciences, (Cedar Rapid, Iowa: Knowledge House, 1992) hal.34-35.
} 
tentang prinsip ilmiah yang mendorong ilmuwan Muslim untuk melakukan eksperimen. ${ }^{27}$

Melalui kegiatan-kegiatan ilmiah inilah, zaman keemasan Islam menemukan fondasinya dalam dunia keilmuan. Kontribusi umat Islam terhadap peradaban umat manusia seperti yang berkembang saat ini, memang bukanlah hasil dari kerja serba biasa. Zaman keemasan ini didapatkan dan diraih oleh ilmuwan/filosuf Muslim dengan cara ekstra keras, seperti halnya Ibn Sina. ${ }^{28}$

\section{Penutup.}

Alur singkat tradisi ilmiah Islam diatas telah memberikan sejumlah gambaran bagi kita umat Islam belakangan ini bahwa peran Islam sebagai sebuah peradaban umat manusia memanglah senyatanya ada. Siapapun boleh mengklaim bahwa otentisitas tradisi keilmuan Islam yang berkembang pada zaman keemasan Islam ini merupakan sesuatu yang bukan murni dihasilkan oleh ilmuwan/pemikir Muslim. Persoalan ini kemudian menjadi sebuah pertanyaan yang kurang layak lagi diperdebatkan ketika kita diperhadapkan pada persoalan akan fungsi eksistensi kita sebagai sarjana Muslim, "Bagaimana seharusnya seorang sarjana Muslim menentukan sikap untuk merespon tantangan masa kini dan masa depan keilmuannya?". Itupun kalau kita hendak menjawabnya dan kalau kita sepakat dengan tesa Arnold J. Toynbee, sejarawan dunia berkebangsaan Inggris yang begitu optimis dengan peran Islam dalam mengawal masa depan peradaban, bahwa perkembangan pada dasarnya adalah "process of challenge and response", dan keberhasilan suatu peradaban berkaitan erat dengan bagaimana manusia pendukungnya menjawab tantangan terkininya. Boleh jadi sampai hari ini tak akan pernah ada ilmu Hadist dan orang akan seenaknya berdalih dengan hadist kalaulah tidak seorang Imam Bukhori dengan penuh keberanian dan ketulusan melakukan riset sepanjang hidup tentang validitas Hadist dan menemukan formulasi canggih metodologi kritik Hadist. Lantas, Bagaimana fungsi ini bergerak ke depan dan kearah manakah fakta sosial bergerak sepanjang

\footnotetext{
${ }^{27}$ A. Koslah, ibid, hal.34-35.

${ }^{28}$ William E. Gohlman (ed.), ibid, hal.27.
} 
kontinum ruang-waktu, kita biarkan sejarah di masa depan berkata. Wallahu a'lam bis Showab!.

\section{DAFTAR PUSTAKA}

al-Jahizh, 1989, Kitab al-Bukhala', Jeddah: Dar al-Mathbu'at al-Haditsah. Amstrong, Karen., 2004, Islam: a Short History, Surabaya: Ikon Teralitera. Atiyeh, George., 1983, Al-Kindi: Tokoh Filosofi Muslim, Bandung: Pustaka. Fakhry, Majid., 1983, A History of Islamic Philosophy, Second Edition, New York \& London: Columbia University Press.

Goadman, L.E., 1992, Avicenna, London \& New York: Routledge.

Gohlman, William E., 1974, The Life of Ibn Sina, Albany: State University of New York Press. (ed.), 1976, The Life of Ibn Sina (Sirah al-Syaikh al-Ra'is), Albany: State of University of New York.

Huff, Toby E., 1995, The Rise of Early Modern Science, Islam, China and the West, New York: Cambridge University Press.

Iqbal, Muhammad., 1981, The Reconstruction of Religious Thought in Islam, New Delhi: Kitab Bhavan.

Kartanegara, Mulyadhi., 2006, Reaktualisasi Tradisi IImiah Islam, Jakarta: Baitul Ihsan.

Koslah, A., 1992, The Miracle of Islamic Sciences, Cedar Rapid, IOWA: Knowledge House.

Kraemer, Joel L. 1986, The Philosophy in the Renaissans of Islam Abu Sulayman al-Sijistani and His Circle, Leiden: E. J. Brill. 1992, Humanism in the Renaisance of Islam, Leiden: E.J. Brill.

Kuhn, Thomas S., 2000, The Structure of Scientific Revolutions: Peran Paradigma dalam Revolusi Sains, Bandung: PT.Remaja Rosda Karya.

Lewis, Bernard., 1980, The World of Islam: Faith, People and Culture, London: Thames and Hudson.

Nakosteen, Mehdi., 1996, Kontribusi Islam atas Dunia Intelektual Barat: Deskripsi Analisis Abad Keemasan Islam, Surabaya: Risalah Gusti.

Pederson, J., 1984, Fajar Intelektualisme Islam: Buku dan Sejarah Penyebaran Informasi di Bani Arab, Bandung: Mizan.

Rosenthal, Franz., 1996, Etika Kesarjanaan Muslim dari al-Farabi hingga Ibn Khaldun, Bandung: Mizan.

Zimmermann, F.W., 1987, Al-Farabi's Commentary and Short Treatise on Aristotle's De Interpretatione,(Oxford: Oxford University Press. 